УДК 811.161.1

Н. И. Самсоненко

\title{
СОПОСТАВЛЕНИЕ ДОМИНАНТНЫХ МОРФОЛОГИЧЕСКИХ ФОРМ И ЗНАЧЕНИЙ КАК СПОСОБ РАЗВЕРТЫВАНИЯ ЛИРИЧЕСКОГО СЮЖЕТА В РУССКОЯЗЫЧНОЙ ПОЭЗИИ
}

\author{
H. I. САМСОНЕНКО. ЗІСТАВЛЕННЯ ДОМІНАНТНИХ МОРФОЛОГІЧНИХ ФОРМ І \\ ЗНАЧЕНЬ ЯК СПОСІБ РОЗГОРТАННЯ ЛІРИЧНОГО СЮЖЕТА В РОСІЙСЬКОМОВНІЙ ПО- \\ E3IÏ. \\ Стаття присвячена розгляду особливостей функціювання одинищь морфологічного рів-
} ня за умов їх згущення на певному текстовому просторі та виявленню того, яку роль відіграє зіставлення домінантних морфологічно різнорідних форм $і$ значень у сукупному формуванні тексто- й змістопородження, а також у загальній ритмізаиії вірша. Поетичний текст, для якого характерні такі способи актуалізаџї граматичних значень, як селекція, співпозиція та атракиія морфологічних форм, допускає накопичення зіставлених різнорідних форм, щзо повторюються на всьому текстовому просторі, формуючі певну структуру, подібну до морфологічної домінанти, але не тотожну ї. Стверджується, щзо згущення різних значень у поетичних текстах, які характеризуються наявністю повторюваних різнорідних морфологічних форм, призводить до зіставлення домінантних морфологічних форм. Зіставлення форм актуалізує виражені ними граматичні значення, що зумовлює посилення комплементарного значення або зіткнення значень з метою створення контрасту, або спричинює виникнення нових контекстуальних значень.

Ключові слова: морфологічна домінанта, поетичний текст, актуалізачія, згущення, атракція, співпозиція, зіставлення.

Н. И. САМСОНЕНКО. СОПОСТАВЛЕНИЕ ДОМИНАНТНЫХ МОРФОЛОГИЧЕСКИХ ФОРМ И ЗНАЧЕНИЙ КАК СПОСОБ РАЗВЕРТЫВАНИЯ ЛИРИЧЕСКОГО СЮЖЕТА В РУССКОЯЗЫЧНОЙ ПОЭЗИИ.

Статья посвящена рассмотрению особенностей функиионирования единии морфологического уровня при их сгущении на определенном текстовом пространстве и выявлению того, какова роль сопоставления доминантных морфологически разнородных форм и категорий в совокупном формировании тексто- и смыслопорождения, а также в общей ритмизации стихотворения. Поэтический текст, для которого характерны такие способы актуализации грамматических значений, как сгущение, соположение и аттракция морфологических форм, допускает наличие разнородных форм, повторяющихся на всем текстовом пространстве, что приводит к формированию стиховой структуры, схожей с морфологической доминантой поэтического текста, но не тождественной ей. В статье утверждается, что сгущение разных значений в поэтических текстах, характеризуюшихся наличием повторяюшихся разнородных морфологических форм, приводит к сопоставлению доминантных морфологических форм. Сопоставление форм актуализирует выражаемые ими грамматические значения, что обусловливает усиление комплементарного значения либо столкновение значений с иелью создания контраста, либо приводит к возникновению новых контекстуальных значений.

Ключевые слова: морфологическая доминанта, поэтический текст, актуализация, сгущение, аттракиия, соположение, сопоставление.

N. I. SAMSONENKO. JUXTAPOTISION OF DOMINANT MORPHOLOGICAL FORMS AND MEANINGS AS A METHOD OF LYRICAL PLOT DEPLOYMENT IN THE RUSSIAN-LANGUAGE POETRY.

The article is aimed to investigate the peculiarities of functioning of morphological units condensed within a certain text space and to identify the role of juxtaposition of dominant morphologically heterogeneous forms and categories in the overall text-and sense formation, as well as in the

() Н.И. Самсоненко, 2019

https://doi.org/10.34142/2312-1572.2019.01.67.06 
general rhythmisation of the poetic text. The poetic text, that is characterized by such ways of grammatical meanings actualisation as condensation, juxtaposition, and attraction of morphological forms, allows for heterogeneous forms to repeat within the text space, which leads to the formation of a poetic structure similar to the morphological dominant of the poetic text, but not identical to it. The article claims that the condensation of different meanings in the poetic texts characterised by the presence of repetitive heterogeneous morphological forms leads to juxtaposition of dominant morphological forms, actualising grammatical meanings that they express, which results in a gain of a complementary meaning or in a collision of meanings to create contrast, or leads to the emergence of new contextual meanings. taposition.

Key words: morphological dominant, poetic text, actualization, condensation, attraction, jux-

Структура лирического произведения представляет собой сложное образование: единицы разных языковых уровней в результате тесного взаимодействия и сложной организации формируют некое «целое, создаваемое соотношением частей, поэтому перед исследователем стоит задача выявления этих частей как речевых единиц, создающих текст» [1, с. 284]. В комплексе разноуровневых языковых средств и их комбинаций, создающих композиционную структуру стихотворения, считаем важным исследовать собственно грамматические средства, которые принимают участие в формировании и передаче глубинных поэтических смыслов. То или иное значение, выражаемое определенной морфологической формой или формами, при условии сгущения этой формы в поэтическом тексте сигнализирует об имплицитном либо явном смысле, который в совокупности с другими языковыми средствами служит развертыванию лирического сюжета, создает экспрессивный потенциал стихотворения и работает на усиление определенного эстетического эффекта. Накопление морфологических единиц одинаковой формы, ее частотный повтор в рамках поэтического произведения или его фрагмента позволяет выделить определенную морфологическую форму как преобладающую на фоне остальных. В таких случаях мы говорим о формировании морфологической доминанты текста, которая является важной и неотъемлемой частью композиционной структуры произведения и участвует в передаче поэтических смыслов $[9 ; 10 ; 11]$.

По нашим наблюдениям, поэтический текст, для которого характерны такие способы актуализации грамматических значений, как сгущение, соположение и аттракция морфологических форм [10; 11], допускает наличие нескольких типов форм, повторяющихся на всем текстовом пространстве, что приводит к формированию стиховой структуры, схожей с морфологической доминантой поэтического текста, но не тождественной ей. Феномен сопоставления доминантных разнородных морфологических форм и значений в структуре лирического произведения и его роль в развертывании лирического сюжета стихотворения последовательно не рассматривались филологами. Данная статья посвящена исследованию особенностей функционирования разнородных единиц морфологического уровня при их сгущении на определенном текстовом пространстве и выяснению того, какова роль сопоставления доминантных морфологически разнородных форм и категорий в совокупном формировании тексто- и смыслопорождения, а также в общей ритмизации стихотворения.

Тексты, характеризующихся наличием повторяющихся разнородных морфологических форм, - явление редкое, но не уникальное. Сгущение разных значений в таких поэтических текстах приводит к сопоставлению доминантных морфологических форм, актуализирующих выражаемые ими грамматические значения, что обусловливает усиление комплементарного значения либо столкновение значений с целью создания контраста, либо приводит к возникновению контекстуальных значений. Примером такого текста может быть стихотворение Даниила Хармса «Летят по небу шарики», в котором представлено сгущение форм множественного числа, настоящего времени и форм творительного падежа:

Летят по небу шарики,

летят они, летят,

летят по небу шарики,

блестят и шелестят.

Летят по небу шарики,

а люди машут им,

летят по небу шарики,

а люди машут им. 


\section{Летят по небу шарики, а люди машут шапками, летят по небу шарики, а люди мащут палками. Летят по небу шарики, а люди машут булками, летят по небу шарики, а люди машут кошками. Летят по небу шарики, а люди машут стульями, летят по небу шарики, а люди машут лампами. \\ Летят по небу шарики, алюди все стоят, летят по небу шарики, блестят и шелестят. \\ А люди тоже шелестят.}

(Даниил Хармс. «Летят по небу шарики...») [13, с. 143-144].

Начальная строка стихотворения Летят по небу шарики повторяется через строку, являясь рефреном произведения. Морфологической доминантой произведения выступает плюральная доминанта, выраженная граммемами множественного числа существительного (щари-

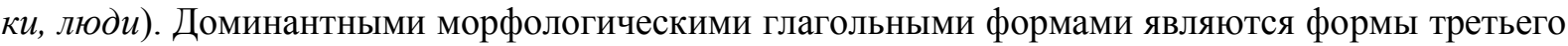
лица множественного числа глаголов настоящего времени (летят, машут, блестят, шелеcmяm, стоят). Единственная повторяющаяся граммема единственного числа небо органично вписана в произведение, поскольку является определенным разделителем художественного пространства. Чередующийся повтор люди машут задает грамматический повтор формы управляемого существительного в творительном падеже: люди машут - шапками, палками, булками, кошками, стульями, лампами. Автор движется от реальной картины к абсурдной и снова к реалистичному настоящему, но грамматическое подобие конструкций делает это движение «естественным».

Лексический повтор, представленный попеременным чередованием строк Летят по небу шарики и люди машут им, объединен общим грамматическим рисунком и является неотъемлемой частью актуализированной доминанты множественного числа. Динамичное движение двух групп однородных объектов, выраженных плюральными граммемами шарики и люди, создает картину отдаленного изображения поступательного и плавного движения в небе (Летят по небу шарики) и периодично повторяющегося движения на земле (а люди машут им). Граммемы множественного числа создают картину, которую можно охарактеризовать как безликую совокупность однородных объектов в небе и на земле. Пространственный план произведения разделен на две части: небо, наполненное шариками, и земля вместе с людьми, которые на ней находятся. Сгущение граммем творительного падежа (а люди машут шапками; а люди машут палками; а люди машут булками; а люди машут кошками; а люди машут стульями; а люди машут лампами) способствует созданию эффекта динамичной абсурдистской картинки на фоне статики земной поверхности.

В основе стихотворения Ольги Надьярной «Время меняется...» [4] лежит синтаксическая схема «подлежащее + сказуемое» с установленной между ними предикативной связью, где сказуемое представлено исключительно глагольными формами настоящего времени. Сплошная глагольная доминанта, задающая грамматический рисунок стихотворения, имеет общий звуковой элемент -mся, являющийся частью флексии глаголов третьего лица единственного числа -ет и глаголов третьего лица множественного числа на -ют и постфикса -ся. Все глаголы являются возвратными, за счет повторения одной и той же морфологической глагольной формы создается динамика чередующихся перемен. Использование форм глагола меняться в начале каждой строфы подчеркивает главную идею стихотворения - постоянные перемены: Время меняется; Люди меняются; Взгляды меняются; Время меняется. Абсолютное начало стихотворения Время меняется, являющееся сильной позицией поэтического произведения, повторяется и в начале последней строфы, усиливая семантику повтора. Динамичная картина перемен, созданная в данном стихотворении лексическими средствами, на грамматическом уровне поддерживается повтором глагольных формантов, образующих глагольную доминанту всего сти- 
хотворения и усиливающих значение цикличности времени и жизни: Время меняется. / Переживается. / И забывается. / Жизнь продолжается.

Определенный контраст создается сопоставлением форм единственного числа первых двух строк первой строфы, последних двух строк третьей строфы и строк четвертой строфы (что создает кольцевое обрамление) с формами множественного числа в середине стихотворения (третья и четвертая строки первой строфы, вторая строфа и первые две строки третьей строфы). Создается чередование фрагментов текста с формами единственного числа (Время меняется. / Боль унимается) и множественного числа (Раны срастаются. / Сны забываются. // Люди меняются. / Судьбы ломаются. / Чувства теряются. / Маски снимаются. // Взгляды меняются. / Мысли метаются.), единственного числа (Что-то находится. / Что-то теряется. // Время меняется. / Переживается. / И забывается. / Жизнь продолжается). Сопоставление фрагментов текста с преобладающими формами единственного / множественного / единственного числа и объединяющие их формы настоящего времени глагола актуализирует значение цикличности и непрерывности жизненного цикла, а также способствует повышению общей ритмизации поэтического текста.

В стихотворении «Присыпаем все раны солью...» Юлии Олефир наблюдаем сгущение форм нескольких падежей, представленных формами винительного (присыпаем раны, присыпаем лицо, моем душу, забываем входные коды, приспускают флаги; И меняем к сердиам пароли; Да за что нам такие роли?/ И зачем нам тогда аншлаги?) и творительного падежей (Присыпаем все раны солью, / Чтоб скорее схватилось коркой, / Чтобы справиться с этой болью... / Моем душу слезами с хлоркой; Присыпаем лиио пылью, / Уверяя себя, что пудрой, / И смиряемся с прошлой былью...) [6, с. 161]. «Морфологический рисунок» стихотворения выглядит как совмещение повторяющихся форм винительного и творительного падежей в первой и четвертой строфах и сгущение винительного падежа во второй и третьей строфах. В данном случае наблюдаем формирование доминанты фрагмента текста, причем доминантных форм две, и они представлены формами винительного и творительного падежей. Творительный падеж в данном произведении представлен как беспредложными, так и предложными формами с предлогом $c$. Беспредложные формы творительного падежа, продиктованные употреблением глаголов npucblnamb, мыльь, указывают на вещество, воспринимаемое как некое «лекарство, средство», способное помочь избавиться от душевных мучений: Присыпаем все раны солью; Моем душу слезами с хлоркой; Присыпаем лицо пылью, / Уверяя себя, что пудрой... Предложно-падежные формы творительного падежа с предлогом $c$ вместе с глагольными формами справиться, смириться способствуют передаче значения преодоления определенного барьера, осознания невозможности изменить прошлое: Чтобы справиться с этой болью...; И смиряемся с прошлой былью...

На рисунок сопоставления доминантных форм падежа накладывается сопоставление числовых форм. Повторяющиеся формы косвенных падежей первой и четвертой строф (в которых преобладают формы творительного и винительного падежей) представлены в основном формами единственного числа женского рода (солью, коркой, болью, душой, хлоркой; пылью, nудрой, былью). Вторая и третья строфы с преобладающими формами винительного падежа представлены формами множественного числа, передающего обобщенное значение жизненных приоритетов и успехов (коды, пароли, годы, роли, аншлаги, награды, флаги).

К повторяющимся формам можно отнести и формы лица, в нашем случае - первого лица множественного числа $\mathrm{Mbl}$. Данная категория реализована в глагольных формах настоящего времени (присыпаем, моем, забываем, меняем, присыпаем, смиряемся), личных местоимениях в форме именительного (мы и тому не $\mathrm{padbl)} \mathrm{и} \mathrm{дательного} \mathrm{падежа} \mathrm{(Да} \mathrm{за} \mathrm{что} \mathrm{нам} \mathrm{такие} \mathrm{роли?}$ / И зачем нам тогда аншлаги? / И за что нам тогда награды?), в местоименияхприлагательных (наши годығ; $B$ нашу честь). Местоимение Б. А. Успенского, «не означает совокупности объектов, каждый из которых может быть обозначен как я), т.е. « $M b l$ не означает 'я + я', но может означать либо 'я + ты' (а также 'я + ты...'), либо 'я + он', 'я + она', 'я + оно', 'я + они'» [12, с. 19]. Mbl в данном случае является максимально обобщенным словом, объединяющим большой круг лиц.

По мнению Ю. М. Лотмана, «чем отчетливее текст направлен на изображение не "эпизода из жизни”, а “сущности жизни”, чем отчетливее он имеет установку на изображение не речи действительности, а ее языка, тем весомее в нем роль местоимений» [3, с. 90]. Трижды повторяющаяся форма личного местоимения первого лица множественного числа в форме дательного падежа нам входит в структуру вопросительных предложений, что, по мнению 
И. И. Ковтуновой, относится к сильным признакам диалога в поэтической речи [2, с. 61]. Под поэтическим диалогом мы, вслед за И. И. Ковтуновой, понимаем не столько художественную передачу устного диалога двух лиц, сколько адресованную речь, ориентированную «на создание сложно организованного письменного текста, который рассчитан на внешнего адресата (читателя)» [2, с. 179]. В данном произведении местоимение мы указывает «на группу лиц, среди которых находится и говорящий» [8, с. 532], т.е. имеет обобщенную семантику, мы включает автора и направлено к максимально широкому кругу адресатов, что на грамматическом уровне поддерживается преобладанием глагольных форм настоящего времени, которые обладают «такими признаками, как незавершенность и обобщенность» [5, с. 267].

Данное стихотворение организовано сопоставлением доминантных форм творительного и винительного падежей, контраст в значении которых поддерживается повтором плюральных граммем и сингулярных граммем женского рода, глагольных форм настоящего времени, а также категории первого лица единственного числа.

Стихотворение Роберта Рождественского «Будь, пожалуйста, послабее...» [7] представляет интересное совмещение трех типов граммем маркированных морфологических категорий в разных фрагментах текста, а именно повелительного наклонения, будущего времени и сравнительной степени прилагательного, роль которых в композиционной структуре произведения разная. Глагольные формы повелительного наклонения вместе с формами сравнительной степени прилагательного введены в сильную стиховую позицию - начальную позицию стихотворения (Будь, пожалуйста, / послабее. / Будь, / пожалуйста.), а также в позицию конца стихотворения (помоги мне в себя поверить, / стань / слабее.), создавая определенное кольцевое обрамление. Форма сравнительной степени прилагательного слабее противопоставляется другим прилагательным в той же форме: Но ведь ты же / сильнее меня, / сильней / и уверенней! Формы сравнительной степени прилагательного выделяются не только за счет заложенной в них экспрессивности, но и за счет синтаксического выделения стилистически нейтральных прилагательных в положительной степени обособленным одиночным согласованным определением (Из горящего дома вынесу / тебя, / сонную. / Я решусь на все неизвестное, / на все безрассудное, - / в море брошусь, / густое, / зловещее...) либо постпозицией прилагательного по отношению к определяемому им существительному (Tbl сама готова спасти других / от уныния тяэккого. / Ты сама не боишься ни свиста пурги, / ни огня хрустящего.).

Повторяющиеся глагольные формы будущего времени являются неотъемлемой составляющей мощных экспрессивных морфологических средств данного произведения. Граммемы будущего времени представлены с двух позиций: от лица лирического героя стихотворения ( $И$ тогда подарю тебе я; И тогда я вымахну, / вырасту, / стану особенным. / Из горящего дома вынесу; Я решусь на все неизвестное, / на все безрассудное, - / в море брошусь, / густое, / зловещее, - / и спасу тебя!.. / Это будет / сердием велено мне...), а также как обращение к тысобеседнику (Не заблудишься, / не утонешь, / зла не накопишь. / Не заплачешь / и не застонешь, / если захочешь. / Станешь плавной / и станешь ветреной, / если захочешь...). Данные глагольные формы будущего времени противопоставлены не только по категории лица, но и по отсутствию / наличию отрицательной частицы не, которая разделяет действия на те, которые произойдут, и те, которые не произойдут.

В данном поэтическом произведении сгущение трех типов морфологических форм (повелительного наклонения, будущего времени глагола и форм сравнительной степени прилагательного) и сопоставление выражаемых ими значений создает мощный экспрессивный эффект, значительно усиливает лексический пласт выразительных средств, способствует развертыванию лирического сюжета.

Стихотворения, помимо сгущения одной морфологической формы, приводящей к формированию морфологической доминанты текста, могут характеризоваться наличием двух и более повторяющихся сопоставленных разнородных морфологических форм (например, форм единственного / множественного числа или женского / мужского рода), что приводит к формированию структуры, схожей с морфологической доминантой, но не тождественной ей. Сопоставление доминантных морфологических форм приводит к актуализации выражаемого ими значения либо к созданию контрастивного значения в рамках поэтического произведения, что играет важную роль в его композиционно-тематической структуре.

Перспективой исследования является изучение экспрессивного потенциала сопоставления доминантных морфологически разнородных категорий и форм в русскоязычной поэзии; исследование особенностей их функционирования в поэтической речи и способности прини- 
мать участие в формировании и передаче особых поэтических смыслов при актуализации единиц морфологического уровня в структуре лирического произведения.

\section{ЛИТЕРАТУРА}

1. Золотова Г. А. Композиция и грамматика // Язык как творчество: Сборник статей к 70-летию В. П. Григорьева. М.: «ИРЯ РАН», 1996. С. 284-296.

2. Ковтунова И. И. Поэтический синтаксис. М.: Наука, 1986. 206 с.

3. Лотман Ю. М. О поэтах и поэзии. С.-Петербург: «Искусство - СПБ», 1996. 848 с.

4. Надьярная О. «Время меняется...». URL: https://www.stihi.ru/2012/12/07/1147 (дата обращени 12.11.2018)

5. Николина Н. А. Категория времени в современной поэтической речи // Поэтика и эстетика слова: Сборник научных статей памяти Виктора Петровича Григорьева / Под ред. 3. Ю. Петровой, Н. А. Фатеевой, Л. Л. Шестаковой. М.: ЛЕНАНД, 2010. С. 262-273.

6. Олефир Ю. Я - кошка. Стихи. Донецк: Издательство «Світ книги», 2013. 164 с.

7. Рождественский Р. «Будь, пожалуйста...». URL: http://rupoem.ru/rozhdestvenskij/ budpozhalujsta-poslabee.aspx (дата обращения 16.11.2018).

8. Русская грамматика. В 2-х т. / Ред. кол. Н. Ю. Шведова и др. М.: Наука, 1980. Т.1. Фонетика. Фонология. Ударение. Интонация. Словообразование. Морфология. 784 с.

9. Самсоненко H.I. Морфологічна домінанта поетичного тексту (на матеріалі російськомовної поезії XIX - XXI століть). Автореф. дис....канд. філол. н. Спеціальність 10.02.02 - російська мова. Харків, 2018.20 с.

10. Скоробогатова Е. А. Грамматические значения и поэтические смыслы: поэтический потенциал русской грамматики (морфологические категории и лексико-грамматические разряды имени): Монография. Харьков: НТМТ, 2012. 480 с.

11. Скоробогатова Е. А. Поэтическая морфология как направление лингвопоэтики и лингвокреативная практика филологического эксперимента // Русская Филология. Вестник Харьковского национального педагогического университета имени Г.С. Сковороды. Харьков, 2018. № 4 (66). С. 3 - 10.

12. Успенский Б. А. Ego Loquens: Язык и коммуникационное пространство. М.: Российск. гос. нгуманит. ун-т, 2007. 320 с.

13. Хармс Д. И. Полет в небеса: Стихи. Проза. Драма. Письма. Л.: «Сов. писатель», $1991.560 \mathrm{c}$. 